\title{
Contralateral Effects and Binaural Interactions in Dorsal Cochlear Nucleus
}

\author{
Kevin A. Davis \\ Departments of Biomedical Engineering and Neurobiology and Anatomy and the Center for Navigation and Communication \\ Sciences, University of Rochester, Rochester, NY 14642, USA
}

Received: 26 January 2005; Accepted: 15 June 2005; Online publication: 2 August 2005

\begin{abstract}
The dorsal cochlear nucleus (DCN) receives afferent input from the auditory nerve and is thus usually thought of as a monaural nucleus, but it also receives inputs from the contralateral cochlear nucleus as well as descending projections from binaural nuclei. Evidence suggests that some of these commissural and efferent projections are excitatory, whereas others are inhibitory. The goals of this study were to investigate the nature and effects of these inputs in the DCN by measuring DCN principal cell (type IV unit) responses to a variety of contralateral monaural and binaural stimuli. As expected, the results of contralateral stimulation demonstrate a mixture of excitatory and inhibitory influences, although inhibitory effects predominate. Most type IV units are weakly, if at all, inhibited by tones but are strongly inhibited by broadband noise (BBN). The inhibition evoked by $\mathrm{BBN}$ is also low threshold and short latency. This inhibition is abolished and excitation is revealed when strychnine, a glycine-receptor antagonist, is applied to the DCN; application of bicuculline, a $\mathrm{GABA}_{\mathrm{A}^{-}}$ receptor antagonist, has similar effects but does not block the onset of inhibition. Manipulations of discrete fiber bundles suggest that the inhibitory, but not excitatory, inputs to DCN principal cells enter the DCN via its output pathway, and that the short latency inhibition is carried by commissural axons. Consistent with their respective monaural effects, responses to binaural tones as a function of interaural
\end{abstract}

Correspondence to: Kevin A. Davis - Department of Neurobiology and Anatomy - University of Rochester • 601 Elmwood Ave., Box 603 Rochester, NY 14642, USA. Telephone: (585) 273-4844; fax: (585) 756-5334; email: Kevin_Davis@urmc.rochester.edu level difference are essentially the same as responses to ipsilateral tones, whereas binaural BBN responses decrease with increasing contralateral level. In comparison to monaural responses, binaural responses to virtual space stimuli show enhanced sensitivity to the elevation of a sound source in ipsilateral space but reduced sensitivity in contralateral space. These results show that the contralateral inputs to the DCN are functionally relevant in natural listening conditions, and that one role of these inputs is to enhance DCN processing of spectral sound localization cues produced by the pinna.

Keywords: dorsal cochlear nucleus, contralateral inputs, binaural interactions, sound localization

\section{INTRODUCTION}

The dorsal cochlear nucleus (DCN) receives afferent input from the auditory nerve (Osen 1970; Ryugo and May 1993) and is thus usually thought of as a monaural nucleus. In response to ipsilateral stimulation, DCN principal cells in cat are well known to exhibit type IV unit response properties (Young and Brownell 1976; Young 1980). Type IV units are excited by low-level best frequency (BF) tones and inhibited by high-level tones, but are excited by broadband noise at all levels. Type IV units also respond with inhibition when a spectral notch is placed at their BF (Spirou and Young 1991). By virtue of their unusual sensitivity to narrowband peaks and notches, such as those added to sounds by the directionally dependent filtering properties of the pinna (Musicant et al. 1990; Rice et al. 1992), DCN principal cells are thought to serve a role in the 
detection of the spatial location of sound sources (Young et al. 1992; Imig et al. 2000). Consistent with this interpretation, lesioning the output pathway of the DCN disrupts the sound orientation behaviors of cats (Sutherland et al. 1998; May 2000).

Several lines of evidence, however, suggest the potential for functionally significant binaural interactions at the level of the DCN. First, anatomic studies have shown that the DCN receives inputs from the contralateral cochlear nucleus (Adams and Warr 1976; Cant and Gaston 1982; Shore et al. 1992; Schofield and Cant 1996; Alibardi 2000; Arnott et al. 2004), as well as descending projections from binaural nuclei (superior olive: Brown et al. 1988; Ostapoff et al. 1997; inferior colliculus: Conlee and Kane 1982; Schofield 2001; auditory cortex: Weedman and Ryugo 1996). Some of these projections are excitatory, whereas others are inhibitory. Moreover, the inhibitory inputs are both glycinergic and GABAergic (Wenthold 1987; Ostapoff et al. 1997; Alibardi 2000). Second, electrical stimulation of the contralateral auditory nerve in an in vitro whole brain preparation produces inhibitory postsynaptic potentials in $80 \%$ of DCN principal cells (Babalian et al. 1999). The latencies of these inhibitory responses are suggestive of mono- and disynaptic connections from the contralateral cochlear nucleus. Finally, single-unit studies have demonstrated that DCN neurons are sensitive to acoustic stimulation of the contralateral ear (Mast 1970, 1973; Young and Brownell 1976; Evans and Zhao 1993; Joris and Smith 1998; Imig et al. 2000). Some units are excited by monaural stimulation of the contralateral ear, but others are inhibited. Limited data suggest that this inhibition is, at least in part, glycinergic (i.e., it is blocked by the glycine antagonist strychnine; Evans and Zhao 1993). In some studies, responses to binaural stimulation are markedly different from those to ipsilateral stimulation suggesting a functional relevance for these binaural interactions (Mast 1970; Young and Brownell 1976), whereas in other studies, the effects are small (Joris and Smith 1998; Imig et al. 2000).

The goals of this study were to gain further information about the nature and effects of contralateral inputs to the DCN by sampling type IV unit responses to a variety of contralateral and binaural stimuli. The results support prior observations that most, but not all, type IV units are inhibited by contralateral stimulation. This inhibition is stronger for noise than for tones, and it is also lower in threshold and shorter in latency. Application of either strychnine or bicuculline (a $\mathrm{GABA}_{\mathrm{A}}$ antagonist) to the recording site blocks this inhibition and reveals underlying excitation; however, only strychnine blocks the onset of inhibition. Manipulations of the acoustic striae suggest that the inhibitory, but not excitatory, inputs to the DCN enter the DCN via its output pathway, and that the short latency inhibition is carried by axons from the contralateral cochlear nucleus. Consistent with the relative strengths of monaural effects, binaural inhibition is stronger for noise than for tones. Compared to monaural responses, binaural responses to virtual space stimuli show enhanced sensitivity to the location of a sound source in ipsilateral space but reduced sensitivity in contralateral space. These results show that contralateral inputs to the DCN are functionally relevant in natural listening conditions, and that one role of these inputs is to enhance DCN processing of spectral sound localization cues produced by the pinna.

\section{METHODS}

Experiments were performed on 11 adult cats (3$4 \mathrm{~kg}$ ) with infection-free ears and clear tympanic membranes. The first nine of these experiments were conducted at Johns Hopkins University (JHU); the last two were conducted at the University of Rochester (UR). All of the following procedures were carried out using similar protocols approved by the Institutional Animal Care and Use Committee of JHU and the University Committee on Animal Resources at the UR.

\section{Surgical procedures}

Cats were anesthetized with ketamine $(40 \mathrm{mg} / \mathrm{kg}$, im) and xylazine $(0.5 \mathrm{mg} / \mathrm{kg}$, im) and were given atropine $(0.05 \mathrm{mg} / \mathrm{kg}, \mathrm{im})$ to minimize respiratory secretions and dexamethasone $(2 \mathrm{mg} / \mathrm{kg}$, im) to reduce cerebral edema. Body temperature was maintained at $39 \pm 0.5^{\circ} \mathrm{C}$ using a regulated heating blanket, and at the UR, breathing and heart rates were monitored. The cephalic vein was cannulated to allow intravenous infusions of fluids, including supplemental doses of ketamine $(15 \mathrm{mg} / \mathrm{kg})$ and xylazine $(0.1 \mathrm{mg} /$ $\mathrm{kg}$ ) as needed (e.g., heart rate over 180 beats/min), and a tracheotomy was performed to facilitate quiet breathing.

A midline incision was made over the skull and the temporalis muscles reflected to visualize the top of the skull and the ear canals. A craniotomy was performed over parietal cortex, and cats were made decerebrate by aspirating the brainstem between the superior colliculus and the thalamus. Anesthesia was then discontinued. The ear canals were transected near the tympanic membrane to accept hollow ear bars for delivering closed-field acoustic stimuli. The animal's head was fixed in the recording position, $35^{\circ}$ nose down with respect to stereo- 
taxic horizontal coordinates, using a headpiece and two ear bars. The left DCN was visualized by removing the skull about the nuchal ridge and aspirating the overlying cerebellum. In some experiments, the cerebellum above the floor of the fourth ventricle was also aspirated to allow access to the acoustic striae. At the end of experiments, cats were euthanized with an overdose of sodium pentobarbital $(100 \mathrm{mg} / \mathrm{kg}$, iv). Some cats were perfused to allow histological confirmation of the completeness of decerebration and of the placement of pharmacological electrodes.

\section{Acoustic stimuli}

Acoustic stimuli were delivered bilaterally via electrostatic speakers that were coupled to hollow ear bars. At the start of each experiment, the frequency response of both systems was measured with a probe tube microphone that was inserted into the ear bars near the tympanic membrane. At JHU, the acoustic calibrations were relatively flat $(\sim 100 \mathrm{~dB}$ SPL $\pm 5 \mathrm{~dB})$ across frequency from $40 \mathrm{~Hz}$ to $40 \mathrm{kHz}$ and similar in both ears $( \pm 2 \mathrm{~dB})$. Therefore, applying equal attenuation to binaural tones of the same frequency was assumed to create a 0 -dB interaural level difference (ILD). At the UR, the attenuations were adjusted separately for the two ears to compensate for any differences in the calibration curves. At both institutions, interaural cross talk was at least $30 \mathrm{~dB}$ (and typically $>50 \mathrm{~dB}$ ) down at all frequencies in the ear opposite to the sound source. The physiologically effective interaural cross talk was measured by means of binaural threshold differences to tones for single auditory nerve fibers and cochlear microphonics (JHU system: Gibson 1982) or for single DCN type IV units (UR system). In the latter case, acoustic crossover was easily detected when the response to high level contralateral tones took the characteristic highly nonmonotonic form elicited by low-level ipsilateral tones.

All test stimuli, including tones, broadband noise, notch noise, and virtual space stimuli, were $200 \mathrm{~ms}$ in duration, gated on and off with $10-\mathrm{ms}$ rise/fall times, and presented once per second. The wideband stimuli were synthesized on-line in the frequency domain and converted to time domain waveforms by taking the inverse Fourier transform of the digitally created noise spectrum (Nelken and Young 1997). Generic head-related transfer functions (HRTFs; Rice et al. 1992) were used to filter broadband noise spectra to synthesize binaural virtual space (VS) stimuli at azimuths ranging from -60 to $+60^{\circ}$ in $15^{\circ}$ steps and elevations from -30 to $+45^{\circ}$ in $7.5^{\circ}$ steps. At the UR, the magnitude spectra of all wideband stimuli were corrected to compensate for nonflat calibration curves. Analog signals were created by playing the waveforms through a 16-bit $\mathrm{D} / \mathrm{A}$ converter at a (usual) sampling rate of $100 \mathrm{kHz}$.

\section{Recording protocol}

All experiments were carried out in a double-walled sound-attenuating booth. Single-unit activity was recorded with platinum-iridium electrodes. At JHU, electrodes were advanced into the DCN using a hydraulic microdrive. The signal from the electrode was amplified $(10,000-30,000 \times)$ and filtered from 0.3 to $6 \mathrm{kHz}$. A variable-threshold Schmitt trigger was used to discriminate action potentials from background noise. At the UR, an Alpha-Omega system was used to advance the electrodes (via a motor-controlled multielectrode positioning system or EPS), to condition the signal (MCP-Plus), and to detect action potentials (template matching software, MSD). In all experiments, spike times relative to stimulus onset were stored for off-line analysis. Sound-driven activity was analyzed in terms of average discharge rates over the final $150 \mathrm{~ms}$ of the stimulus-on interval to reflect steady-state responses; spontaneous rates were computed over the last $400 \mathrm{~ms}$ of the stimulus-off interval of each 1-s stimulation period.

Recording electrodes were advanced dorsoventrally through the DCN, whereas 50-ms search tones or noise bursts were presented to the ipsilateral ear. When a single unit was isolated, its BF and threshold were determined using audiovisual feedback, and its response type was determined from responses to 200ms BF-tone and broadband noise bursts presented across a range of sound levels (100-dB range in 1-dB steps). Units were classified as type IV, IV-T, III, II, or complex spiking using standard criteria (e.g., Shofner and Young 1985; Zhang and Oertel 1993a; Manis et al. 1994). Results are primarily reported for type IV units because DCN principal cells in cat usually exhibit these response properties (Young 1980). Once a unit was classified, rate-level functions were obtained for tones (at the ipsilateral $\mathrm{BF}$ ) and broadband noise presented to the contralateral ear. Frequency response maps for contralateral tones were created by sweeping the frequency of tone bursts over a threeoctave range centered on the unit's ipsilateral BF. These sweeps were presented at multiple sound levels, ranging from 0 to $60 \mathrm{~dB}$ above threshold. Each frequency-intensity combination was presented once.

The pharmacology of the contralateral inputs to the DCN was investigated by infusing the recording site with either the glycine antagonist strychnine or the $\mathrm{GABA}_{\mathrm{A}}$ antagonist bicuculline. Piggyback multibarreled electrodes (after Havey and Caspary 1980) were used to deliver strychnine hydrochloride or bicuculline methiodide (each $10 \mathrm{mM}$, pH 3.5-4.0, Sigma) into the DCN (Davis and Young 2000). Electrode 
negative retention currents of $20 \mathrm{nA}$ and ejection currents of $50 \mathrm{nA}$ were produced with microiontophoresis constant current generators. Rate-level functions for contralateral $\mathrm{BF}$ tones and broadband noise bursts were performed before and after pharmacological manipulations to verify unit stability and to confirm recovery from inhibitory blockade before moving on to the next unit.

The origin of contralateral effects in the DCN was studied using both pharmacological and surgical manipulations of the dorsal output tracts (dorsal and intermediate acoustic striae). Hypodermic needles (30 gauge) were used to record from, and to deliver solutions of, lidocaine hydrochloride (2\%; Tech America) into the contralateral DAS/IAS and DAS. Needles were coupled to a 1-ml syringe to allow reliable injections of microliter amounts of lidocaine solution. The needles were either placed at the medial border of the contralateral DCN, where the fibers of the DAS and IAS intermingle, or moved medial toward the midline of the floor of the fourth ventricle to isolate the DAS (Fernandez and Karapas 1967; Davis 2002). Placement of the needle was guided by searching for noise-evoked background activity where the output tracts were expected to be found. The needle was placed in a position judged to the center of the $\operatorname{tract}(s)$ (i.e., where there was the maximum background activity), and then left there for the entire experiment. In some of these experiments, the medial border of the ipsilateral DCN was aspirated to sever fibers incoming through the ipsilateral DAS/IAS.

For binaural testing, two paradigms were used. First, the same pure tone or broadband noise stimulus was presented to both ears, but a 40-dB range of ILDs was created by varying the level of the contralateral stimulus relative to a fixed ipsilateral stimulus. The intensity of the ipsilateral stimulus was fixed at 10-dB re threshold. Second, responses were obtained to ipsilateral monaural and binaural VS stimulation. The sampling rate for these stimuli was set on a unitby-unit basis to $(\mathrm{BF} / 12) \times 100 \mathrm{kHz}$. This stimulus manipulation, which effectively shifted the BF of each unit under study to $12 \mathrm{kHz}$, was performed because $12 \mathrm{kHz}$ is near the center of the frequency range (5$18 \mathrm{kHz}$ ) where cat HRTFs show directionally dependent spectral notches (Musicant et al. 1990; Rice et al. 1992). Furthermore, it increased the yield of data at one frequency and thereby allowed the data to be subjected to statistical analyses.

\section{RESULTS}

The effects of contralateral monaural stimulation with pure tones and broadband noise $(\mathrm{BBN})$ were studied on 54 type IV units. To examine further the nature and origin of the contralateral inputs to the DCN, different subsets of these units were tested under local blockade of inhibitory receptors $(n=8)$ and after manipulations of the dorsal output tracts $(n=$ 18). Binaural interaction data were acquired on 20 units.

\section{Effects of contralateral monaural acoustic stimulation on type IV units}

Frequency response maps for contralateral tones were obtained for 10 type IV units. Five of these units showed evidence of inhibitory effects, three showed strictly excitatory effects, and two showed no effects. Response maps for a unit inhibited by contralateral tones and a unit excited by tones are shown in Figure $1 \mathrm{~A}$ and $\mathrm{B}$, respectively. In these plots, inhibitory areas (gray fill) are defined as stimulus conditions that elicited responses $\geq 1$ standard deviation (SD) below the average spontaneous rate (SR; horizontal lines); similarly, excitatory areas (black fill) indicate tone-driven rates $\geq 1 \mathrm{SD}$ above the SR. Inhibited units (Fig. 1A) have narrow Vshaped inhibitory areas that widen slightly about unit $\mathrm{BF}$ (vertical line) with increasing sound levels. This inhibition may, as shown here, or may not be flanked on both sides by excitation. Excited units (Fig. 1B) show broad V-shaped excitatory areas centered on $B F$. These units do not show inhibitory responses to pure tones. The BFs for ipsilateral tones are indicated by the arrows at the top of these plots. In all cases showing a response, the BFs for contralateral and ipsilateral tones differed by less than 0.2 octaves.

The responses of type IV units to stimulation of the contralateral ear can be divided into four groups based on the patterns of excitation and inhibition revealed in their rate versus level functions for pure tones (at the ipsilateral $\mathrm{BF}$ ) and BBN. Representative data for each class are shown in Figure 2, where responses to tones are shown with thin solid lines and responses to noise are shown with heavy solid lines. In these plots, a response was said to be excitatory (inhibitory) if the maximum driven rate was $1 \mathrm{SD}$ above (below) the SR. Responses with thresholds greater than $40 \mathrm{~dB}$ above ipsilateral thresholds to the same stimulus were rejected because of the possibility of cross talk. Most units were strongly inhibited by BBN (50/54 cases), and most of these were also weakly (16/50; class ii; Fig. 2A), if at all (28/50; class oi; Fig. 2B), inhibited by tones; the remainder were excited by tones (6/50; class ei; Fig. 2C). Only 4 of 54 units were excited by noise, and all of these were also excited by tones (class ee; Fig. 2D). No relationship was found between unit class and BF (from 4 to $40 \mathrm{kHz}$ ). However, units inhibited by tones were more likely to be located closer to the surface of the 
A
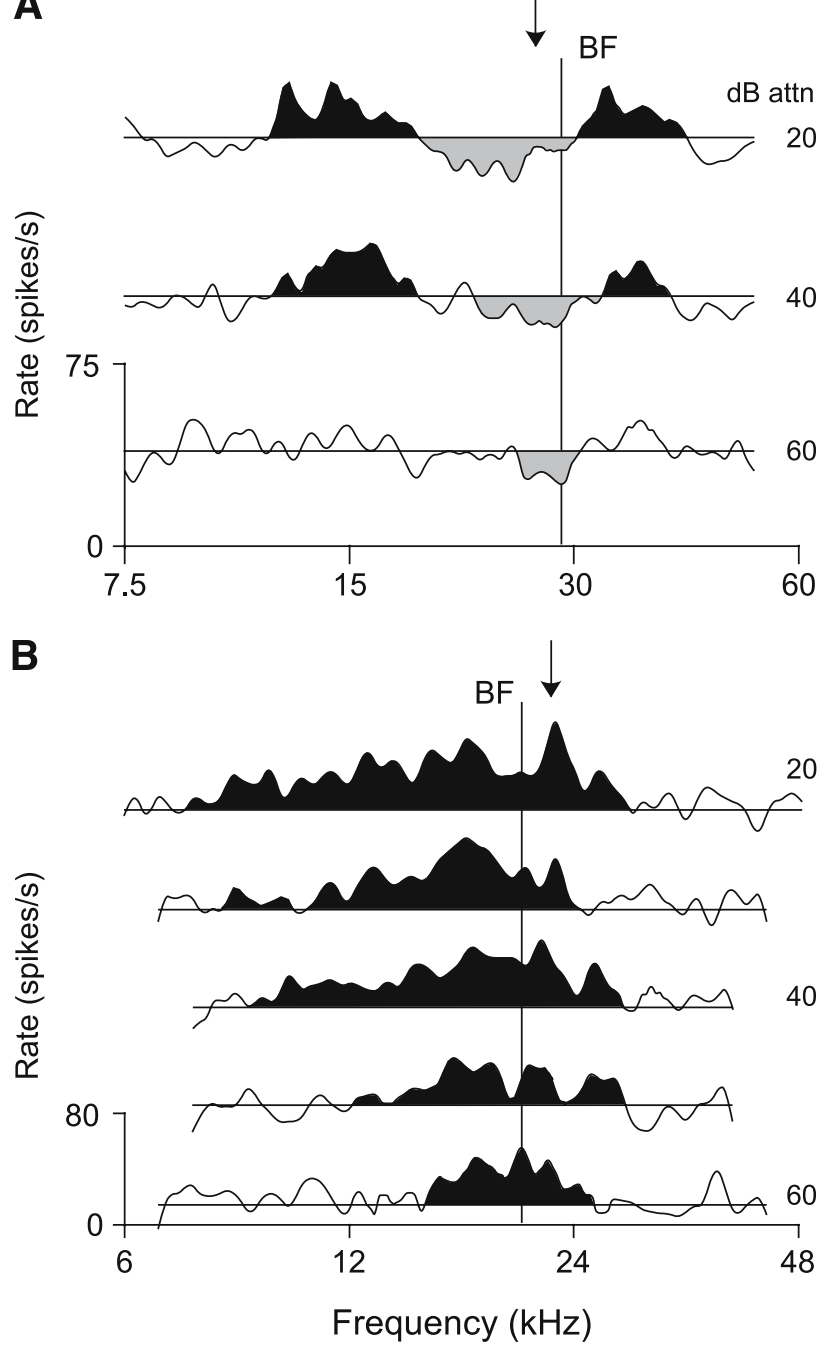

FIG. 1. Contralateral monaural frequency response maps for type IV units in the dorsal cochlear nucleus (DCN). (A) A unit showing inhibition to contralateral tones (98/05/28, unit 4.01); (B) a unit showing excitation (99/03/22, unit 5.02). Stimulus-driven rates are plotted against frequency at multiple sound levels (numerical labels on right). Horizontal lines indicate average spontaneous rates (SR). Black (gray) regions identify excitatory (inhibitory) response areas. Sound levels are given in $\mathrm{dB}$ attenuation; actual sound pressure level $(\mathrm{SPL})$ varies with the acoustic calibration, but $0 \mathrm{~dB}$ attn. is near 100 $\mathrm{dB}$ re $20 \mu \mathrm{Pa}$ for tones. Solid vertical lines indicate BFs to contralateral tones; the arrows at the top of the plots mark ipsilateral BFs.

DCN, whereas units excited by tones were usually found in deep DCN $(P<0.05$, Kruskal-Wallis test).

A summary of the magnitude of effects for all units tested is shown in Figure 3, which plots each unit's maximum driven rate to noise against its maximum tone-driven rate; the dashed line indicates equal driven rates to both stimuli. The different symbols used to plot the points represent the four classes of response. Note that all of the data points lie below the equity line. For class ii units (unfilled circles), this indicates that the inhibitory response to noise was always stronger than that to tones. Conversely, for type ee units (black-filled squares), the excitatory response to tones was stronger than that to noise. There were no units that were inhibited by tones and excited by noise. Nonparametric statistical tests indicated no relationship between unit class and SR ( median $=56$ spikes $/ \mathrm{s}, P>0.05$, Kruskal-Wallis test $)$. In addition, there was no significant difference in the maximum noise-driven rates among class ii, oi, and ei units (circles; 44 spikes/s; $P>0.05$, Kruskal-Wallis test) or in the tone-driven rates of class ei and ee units (black-filled symbols; 60 spikes/s; $P>0.05$, Mann-Whitney $U$-test).

Each unit's threshold for contralateral tones is plotted against its threshold for ipsilateral tones in Figure 4A. Similarly, each unit's threshold for contralateral and ipsilateral $\mathrm{BBN}$ is compared in Figure 4B. Contralateral thresholds for tones greater than $40 \mathrm{~dB}$ above ipsilateral thresholds are considered suspect, and symbols for such units have been plotted above the ordinate (class oi units, gray-filled circles). Note that all of the data points for tones are well above the equity (dashed) line, whereas many data points for noise are near the line, indicating that threshold differences were usually smaller for noise than for tones. In fact, 12 units had contralateral noise thresholds that were below corresponding ipsilateral thresholds (points below the dashed line); no units showed a lower threshold to contralateral tones than to ipsilateral tones. Overall, the median difference in thresholds was $8 \mathrm{~dB}$ for noise, whereas it was $18 \mathrm{~dB}$ for units that were sensitive to contralateral tones (excludes class oi units).

To examine the time course of contralateral effects, poststimulus time histograms (PSTHs) were constructed from the rate-level responses of individual units at stimulus levels that elicited similar, nearmaximum effects (typically, levels $\geq 20 \mathrm{~dB}$ re threshold). Figure 5A shows PSTHs of the responses to 200ms tone (solid lines) and noise bursts (heavy solid lines) for the representative class ii unit (rate-level curves shown in Fig. 2A) that was otherwise firing spontaneously. Note that the inhibitory response to tones built up over time and reached its full strength within 50-60 ms. In contrast, the response to noise showed a short-latency, sharp onset to inhibition and a sustained reduction of driven rate. Poststimulus time histograms for the representative class ee unit (Fig. 2D) are shown in Figure 5C. For this unit, the tone response showed a well-defined onset and sustained excitation. The noise response showed an initial, short-latency decrease in rate, followed by an increase in rate at a latency comparable to that to tones.

Each unit's latency for contralateral tones (noise) is plotted against its latency for ipsilateral tones (noise) in Figure 5B and D, respectively. As above, 

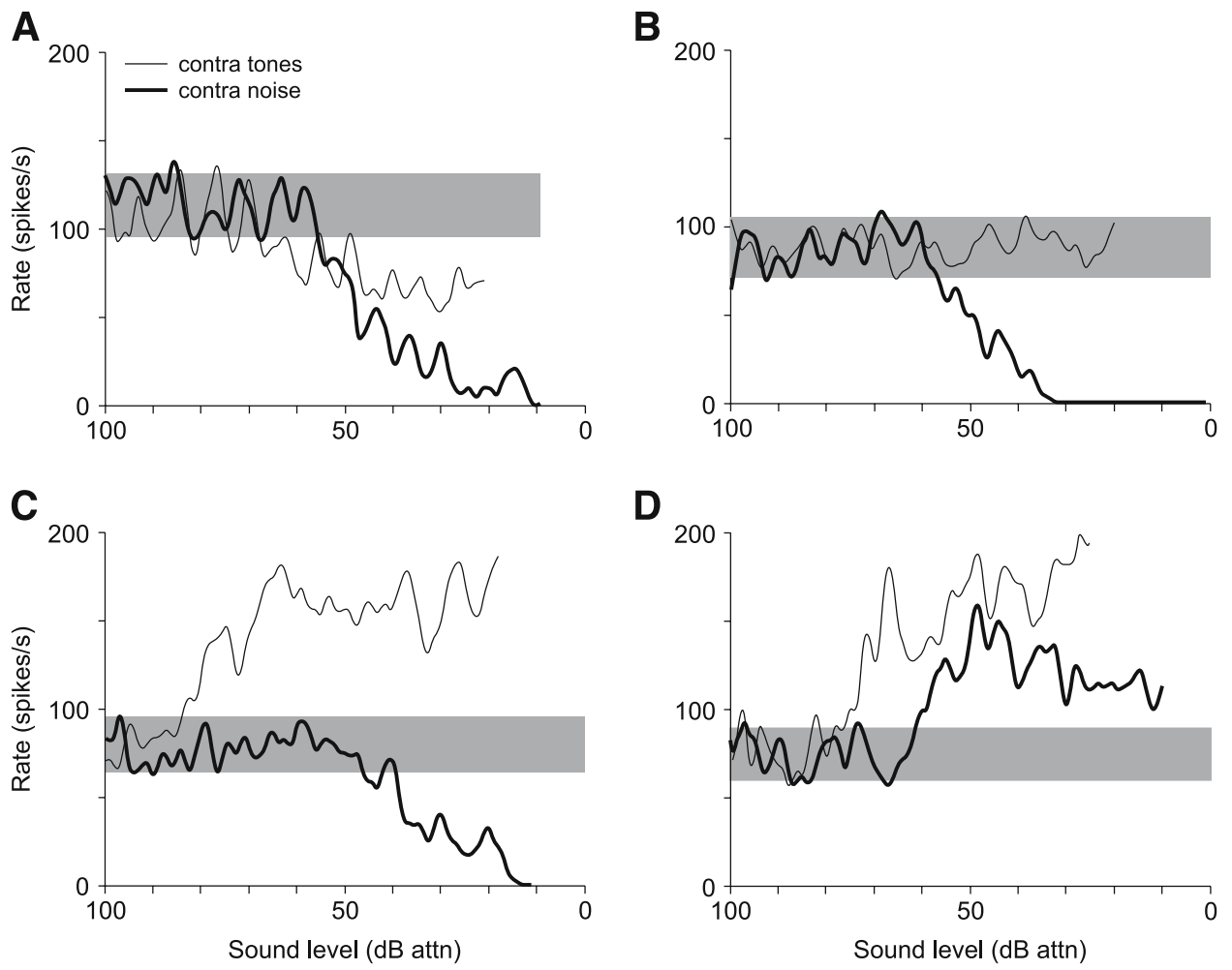

FIG. 2. Range of responses to contralateral stimulation among DCN type IV units. Plots show discharge rate vs. level in response to tones (at the ipsilateral BF; thin lines) and broadband noise (heavy lines) presented to the contralateral ear. Sound levels are shown in $\mathrm{dB}$ attenuation $(0 \mathrm{~dB}$ attn. is near $100 \mathrm{~dB} S \mathrm{SL}$ re $20 \mu \mathrm{Pa}$ for tones and near $40 \mathrm{~dB}$ spectrum level re $20 \mu \mathrm{Pa} / \sqrt{ } \mathrm{Hz}$ for noise). Shaded bars show the range of SR for these units. Class ii units $(\mathbf{A})$ are inhibited

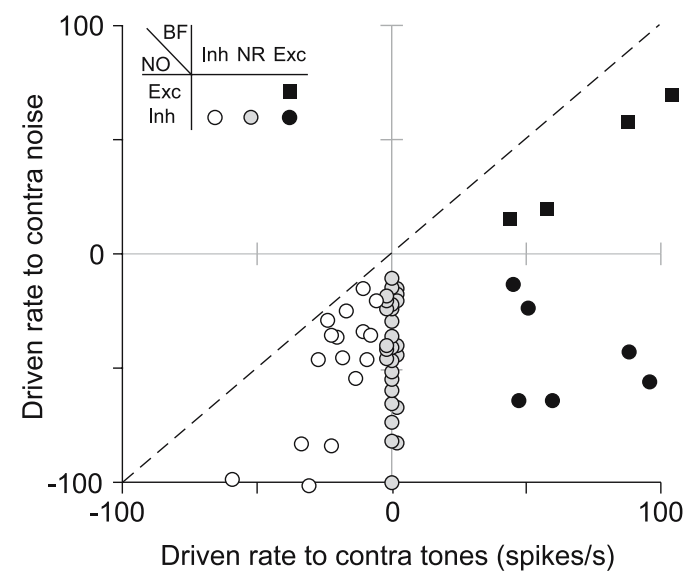

FIG. 3. Magnitude of contralateral effects on DCN type IV units. Comparison of each unit's maximum driven rate for noise vs. tone stimulation. The symbol used to plot each point indicates the effect that contralateral stimuli had on the unit (see legend). Data points along the center ordinate are shifted slightly to avoid overlap. The dashed line indicates equal driven rates to both stimuli. Note that most units are weakly, if at all, inhibited by tones but are inhibited strongly by contralateral noise (open and gray circles).

by both tones and noise (98/09/02, unit 5.04, BF=16.5 kHz); class oi units (B) are unaffected by tones and inhibited by noise $(99 / 07 / 08$, unit 5.06, $\mathrm{BF}=27.5 \mathrm{kHz})$; class ei units $(\mathbf{C})$ are excited by tones but inhibited by noise $(98 / 05 / 28$, unit $2.02, \mathrm{BF}=12.2 \mathrm{kHz})$; and class ee units (D) are excited by both tones and noise (99/03/22, unit 7.03, $B F=15.4 \mathrm{kHz}$ ).

symbols for units without a response to contralateral tones are plotted beyond the axes. Here, response latency is defined as the time from stimulus onset to the first time the driven rate in the PSTH exceeded 1 SD above (below) the SR. Two symbols (asterisks and squares) are plotted for each class ee unit in Figure $5 \mathrm{D}$ to highlight the dual nature of the response (inhibition followed by excitation) to contralateral noise exhibited by this class of units. Note that all of the data points for tones are above the equity (dashed) line, whereas most data points for noise are distributed along the line (including 19 units with contralateral noise latencies below corresponding ipsilateral values) indicating that latency differences were usually smaller for noise than for tones. Overall, the median difference in latency was $10 \mathrm{~ms}$ for tones but only $2 \mathrm{~ms}$ for noise. However, the unit classes did show some differences in response properties. For example, class ii units (unfilled circles) showed a wide range of latencies for contralateral tones, whereas class ei and ee units (filled symbols) showed a tighter cluster of values at intermediate latencies. In addition, units excited by contralateral noise (class ee; 


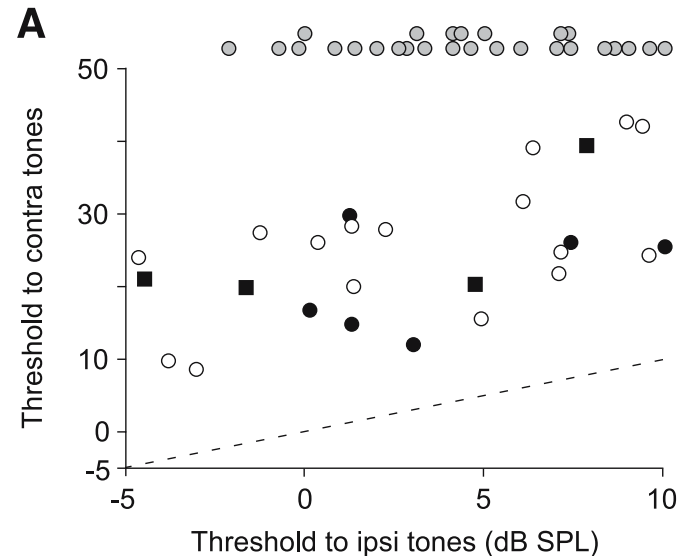

B

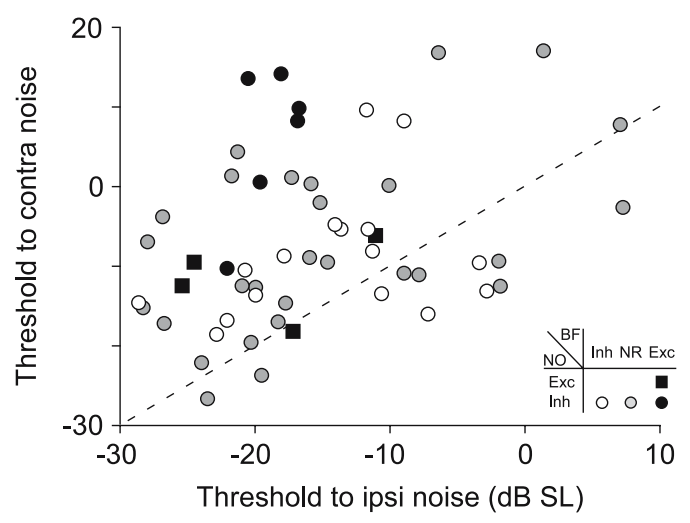

FIG. 4. Threshold of contralateral effects on DCN type IV units. Comparison of each unit's threshold to contralateral vs. ipsilateral tones (A) and noise (B). The symbol used to plot each point indicates the effect that contralateral stimuli had on the unit (see legend in $\mathbf{B}$ ). Contralateral thresholds greater than $40 \mathrm{~dB}$ above ipsilateral thresholds to the same stimulus were rejected due to the possibility of cross talk; symbols for such units are plotted above the ordinate. Dashed lines show points of equal threshold. Note that threshold differences for noise are usually smaller than those for tones.

black squares) showed longer latencies for contralateral noise than did units inhibited by noise $(P>0.05$, Mann-Whitney U-test).

Effects of contralateral monaural acoustic stimulation on other unit types

The effects of contralateral monaural stimulation with pure tones and BBN were studied on 3 type IVT, 10 type III, 7 type II, and 5 complex-spiking units. The type IV-T and type III units exhibited all four classes of response with threshold and latency differences similar to those exhibited by type IV units. The type II units, on the other hand, appeared unresponsive to monaural stimulation of the contralateral ear; that is, driven rates were unchanged from zero, which is the SR of this unit type. If background activity was evoked in these units using low-level ipsilateral BF tones, then these units exhibited weak class ei properties. Furthermore, the excitation to contralateral tones was tuned about the ipsilateral BF (not shown). Finally, complex-spiking units exhibited little-or-no affect of contralateral stimulation.

\section{Pharmacology of contralateral inhibitory inputs}

Strychnine $(n=5)$ and bicuculline $(n=4)$ were applied to recording sites in the DCN to assess how glycinergic and GABAergic inhibitory inputs shape the sensitivity of type IV units to contralateral stimuli, particularly BBN. The results of these pharmacological manipulations are summarized for a representative unit in Figure 6. In this case, strychnine was applied to the site first, the unit was allowed to recover for $1 \mathrm{~h}$ after data collection was completed (recovery curves not shown), and then bicuculline was applied. Prior to drug administration, the type IV unit was strongly inhibited by contralateral BBN (Fig. 6A; heavy solid line). In the presence of strychnine (solid line), the unit lost entirely its inhibitory response to high-level noise. Furthermore, the unit now showed a weak excitatory response. A similar change in response was observed in the presence of bicuculline (dashed line). For this unit, bicuculline also increased the SR of the unit (heavy gray bar vs. light gray bar).

Poststimulus time histograms showing the time course of the effects of these inhibitory antagonists on the response of the type IV unit are shown in Figure 6B. Under control conditions (heavy solid line), the PSTH showed a typical short-latency, sharp decrease in rate, followed by a sustained reduction throughout the stimulus duration. It also showed an unusually long, poststimulus suppression in rate that took several hundreds of milliseconds to recover back to SR. Under strychnine (solid line), the short-latency inhibitory response was blocked, and the initial response was excitatory. With time, the magnitude of this excitatory response decreased, and by the end of the stimulus, the unit was inhibited. In contrast, bicuculline (dashed line) did not block the shortlatency component of the inhibition. Thereafter, its effects were similar to that of strychnine.

\section{On the origins of contralateral effects}

One potential extrinsic source of glycinergic inhibition within the DCN is large stellate cells in the contralateral ventral cochlear nucleus (VCN) (e.g., Schofield and Cant 1996; Wenthold 1987). Anatomical evidence suggests that the axons of these neurons exit the contralateral VCN near the fibers of the dorsal (DAS) and intermediate acoustic striae (IAS), turn sharply ventral before crossing the midline, and enter the ipsilateral DCN via the DAS (Schofield and 
A

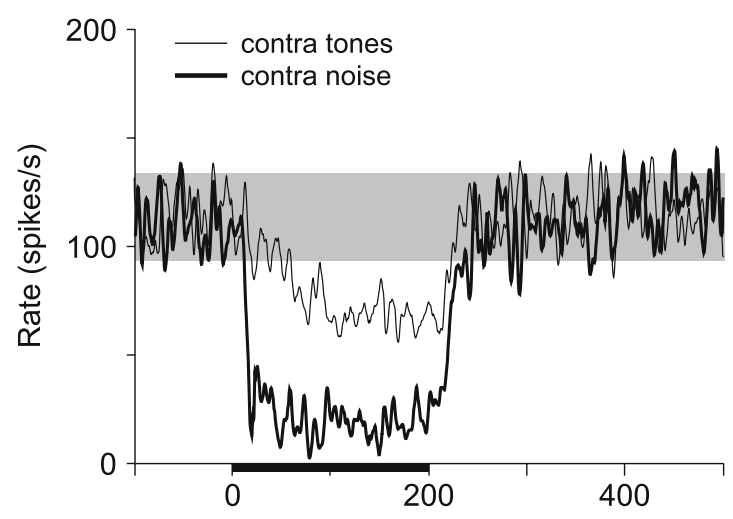

C

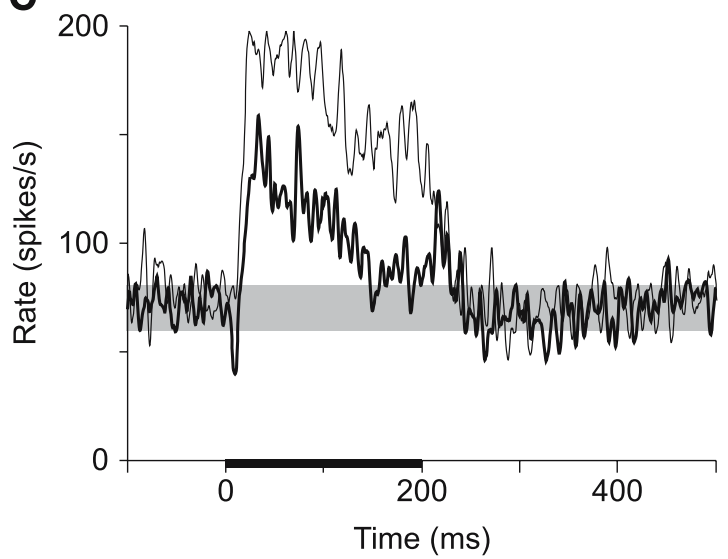

FIG. 5. Time course of effects of contralateral tones and noise on DCN type IV units. A, C: Plots show discharge rate vs. time for an individual class ii (A: 98/09/02, unit 5.04, BF=16.5 kHz) and class ee unit (C: 99/03/22, unit 7.03, BF $=15.4 \mathrm{kHz}$ ). Poststimulus time histograms (PSTHs) show effects of contralateral stimuli on the spontaneous activity of the unit; the range of SR is shown by the shaded bar. PSTHs were constructed from rate-level responses of units at stimulus levels that elicited similar, near-maximum, effects (typically, levels $\geq 20 \mathrm{~dB}$ re threshold). The duration of the stimulus is

Cant 1996; Arnott et al. 2004). Figure 7 shows the effects on representative type IV units of pharmacological and surgical manipulations of the dorsal fiber tracts at two locations. The results in Figure 7A and $\mathrm{C}$ were obtained before and after lidocaine was applied to the medial border of the contralateral DCN $(n=5)$, i.e., where the fibers of the DAS and IAS are in close proximity. Under control conditions (heavy solid line), the type IV unit was strongly inhibited by contralateral BBN (Fig. 7A). After lidocaine was applied, the response became excitatory at low stimulus levels and only weakly inhibitory at high levels. The PSTH constructed from the lidocaine response shows that the short-latency component of inhibition in the control response (Fig. 7C; heavy solid line) was blocked by the lidocaine injec-
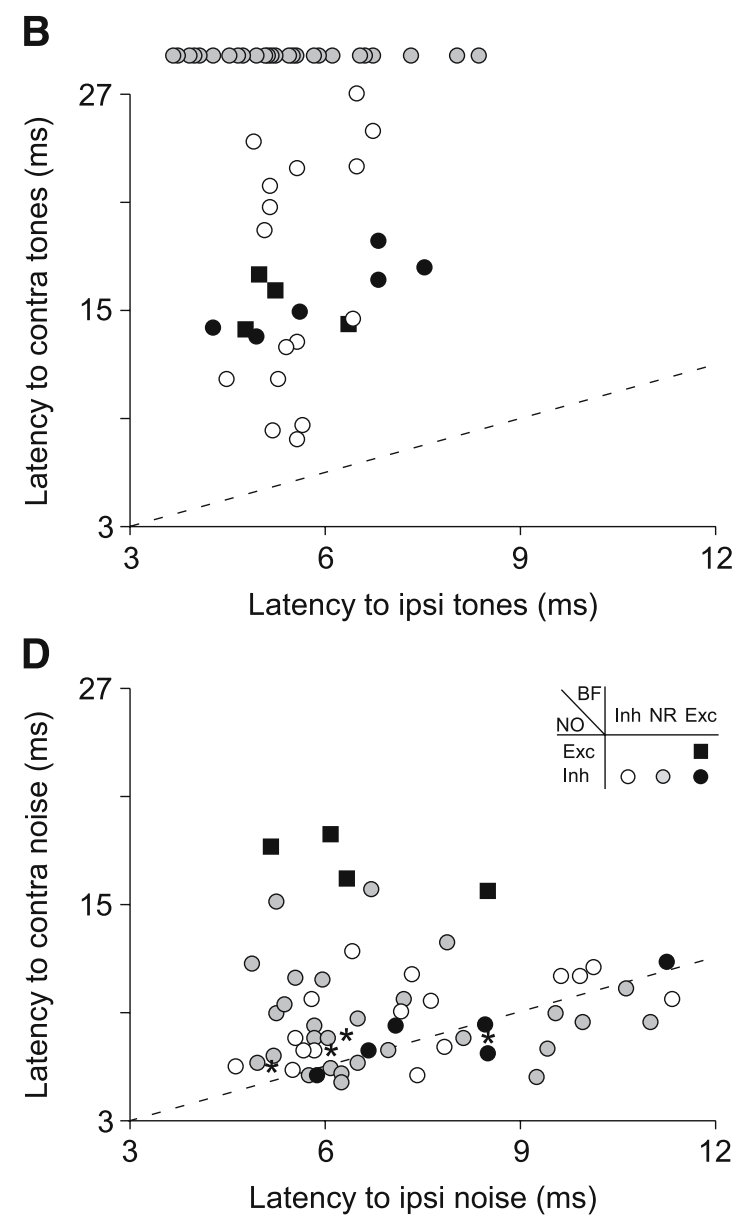

marked by the black bar below the abscissa. B, D: Scatter plots of contralateral vs. ipsilateral latencies for tones (B) and noise (D) for all units. Symbols indicate the effect of contralateral tones and noise on each unit (see legend in D). Two symbols (asterisks and filled squares) are plotted for each class ee unit in panel $\mathbf{D}$ to highlight the dual nature of the response (inhibition followed by excitation) to contralateral noise. Dashed lines indicate equal latency. Note that latency differences for noise are usually smaller than those for tones.

tion (solid line). Blockade of the contralateral DAS alone $(n=7)$ had no effect (results not shown) suggesting that short-latency inhibition arises from axons coursing in, or near, the contralateral IAS.

Figure $7 \mathrm{~B}$ shows the rate-level response of a type IV unit to contralateral BBN after the medial border of the ipsilateral DCN was lesioned. This manipulation severs both dorsal output tracts from the cochlear nucleus. The unit was strictly excited by contralateral BBN (and tones, not shown) at all levels. Unlike typical class ee units, however, the PSTH for this unit exhibited no short-latency inhibition prior to the excitatory response (Fig. 7D). All units tested after this manipulation $(n=6)$ showed similar response properties suggesting that the axons carrying inhibition, but not excitation, enter the DCN via 
A

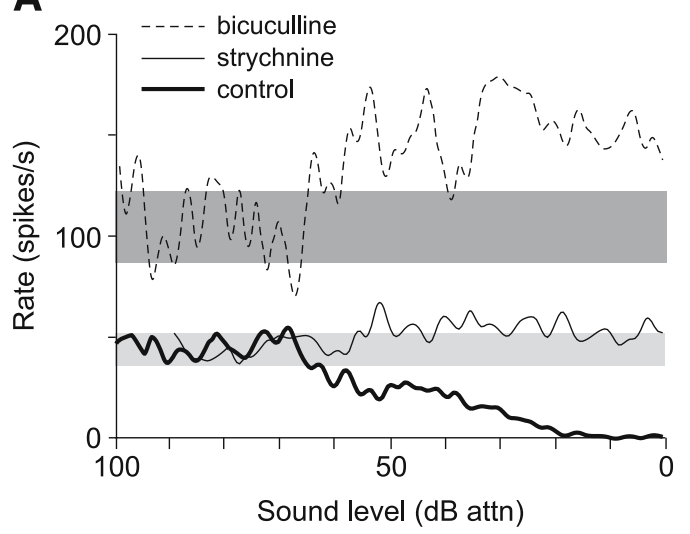

B

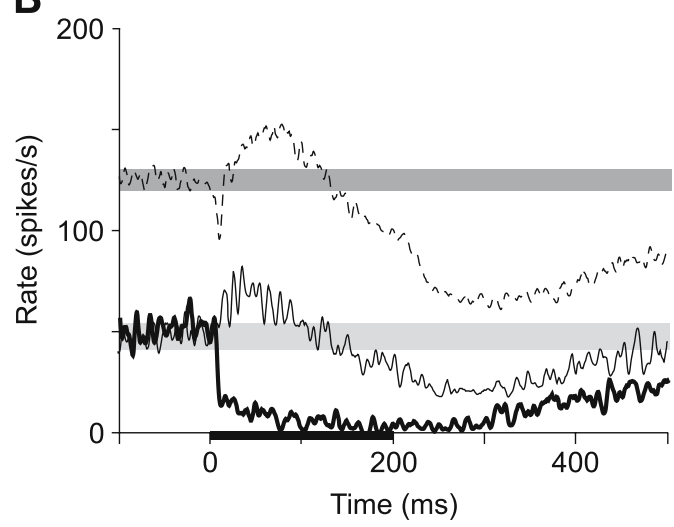

FIG. 6. Effects of strychnine and bicuculline on the rate-level function (A) and PSTH (B) of a DCN type IV unit (12/14/98, unit $1.02, \mathrm{BF}=16 \mathrm{kHz}$ ) in response to contralateral broadband noise. In both panels, responses before iontophoretic application of any agent (control condition) are shown as heavy solid lines, responses under strychnine are shown as thin solid lines, and responses under bicuculline are shown as dashed lines. Shaded bars show the range of SR for this unit before (light shading) and during (heavy shading) application of a drug; in this case, the SR changed only under bicuculline. Note that application of either strychnine or bicuculline blocks the net inhibitory response of the type IV unit to contralateral noise and reveals underlying excitation (A). Both agents show their largest affects over the initial time course of the response (B); however, only strychnine abolishes the onset of inhibition.

the DAS. The fact that inhibitory and excitatory inputs enter the DCN via dorsal and ventral routes, respectively, may explain the observation reported here and by Mast $(1970,1973)$ that neurons inhibited by contralateral tones predominate in the middle (fusiform cell) layer of the DCN, whereas excited neurons tend to be located in the deep layer of the DCN.

\section{Effects of binaural stimulation on type IV units}

Contralateral effects can alter substantially the responses of type IV units to ipsilateral stimuli. Figure $8 \mathrm{~A}$ shows interaural level difference (ILD) functions for a representative type IV unit (class ii) in response to tones and noise. These functions were created by presenting a $10-\mathrm{dB}$ re threshold stimulus to the ipsilateral ear while varying the intensity of that stimulus in the contralateral ear across a \pm 20 -dB range of levels. By convention, positive ILDs indicate stronger sounds at the excitatory (ipsilateral) ear. In response to binaural tones (dashed line), the firing rates of the type IV unit remained relatively constant across all levels of contralateral stimulation because responses were dominated by the excitatory response to the fixed ipsilateral tone. By contrast, the discharge rates to binaural BBN (solid line) decreased when the balance of inputs shifted toward inhibition at increased levels of contralateral stimulation (negative ILDs).

The effects of ILD on the discharge rate properties of type IV units were quantified by comparing the driven rates at ILDs of $\pm 20 \mathrm{~dB}$ for binaural tones (Fig. 8B) and noise (Fig. 8C). Each symbol in these plots indicates the driven rate of an individual unit at the $-20-\mathrm{dB}$ versus the $+20-\mathrm{dB}$ condition, with symbols falling along the dashed line representing units that showed no change in rate under the two conditions. Different symbols represent the different response classes. Consistent with qualitative observations for the representative unit in Figure 8A, the rate changes for tones were small for all units tested $(n=10$; Fig. $8 \mathrm{~B}$ ), as indicated by the fact that the symbols are clustered about the equity line. Conversely, rate changes for BBN were large (Fig. 8C), with a median change in rate of 45 spikes/s. Furthermore, for 4 of the 19 units showing inhibition to contralateral BBN (circles), the unit's driven response changed from excitation to inhibition (symbols below the horizontal line) suggesting a strong functional relevance for these binaural interactions.

The threshold for transition from a contralateral to ipsilateral dominant response has been defined as the half-maximal ILD (Wenstrup et al. 1988; Park and Pollak 1993; Davis et al. 1999). The half-maximal ILD is defined to be that ILD at which the driven response to the binaural stimulus changes by $50 \%$ from the response evoked by the excitatory monaural stimulus. Using this definition, no units exhibited a transition in response to tones. This was true despite the fact that the level of the contralateral tone in the -20-dB ILD condition was more than $10 \mathrm{~dB}$ above the median monaural threshold of the population. By contrast, most units exhibited a transition for noise $(17 / 20$ units), with the median half-maximal ILD equal to $-4 \mathrm{~dB}$. Given that the intensity of the contralateral noise in the $0-\mathrm{dB}$ ILD condition was just above the median monaural threshold of the population, this result suggests that only a modest increase in contralateral stimulus level above threshold was needed to attain the half-maximal ILD. 

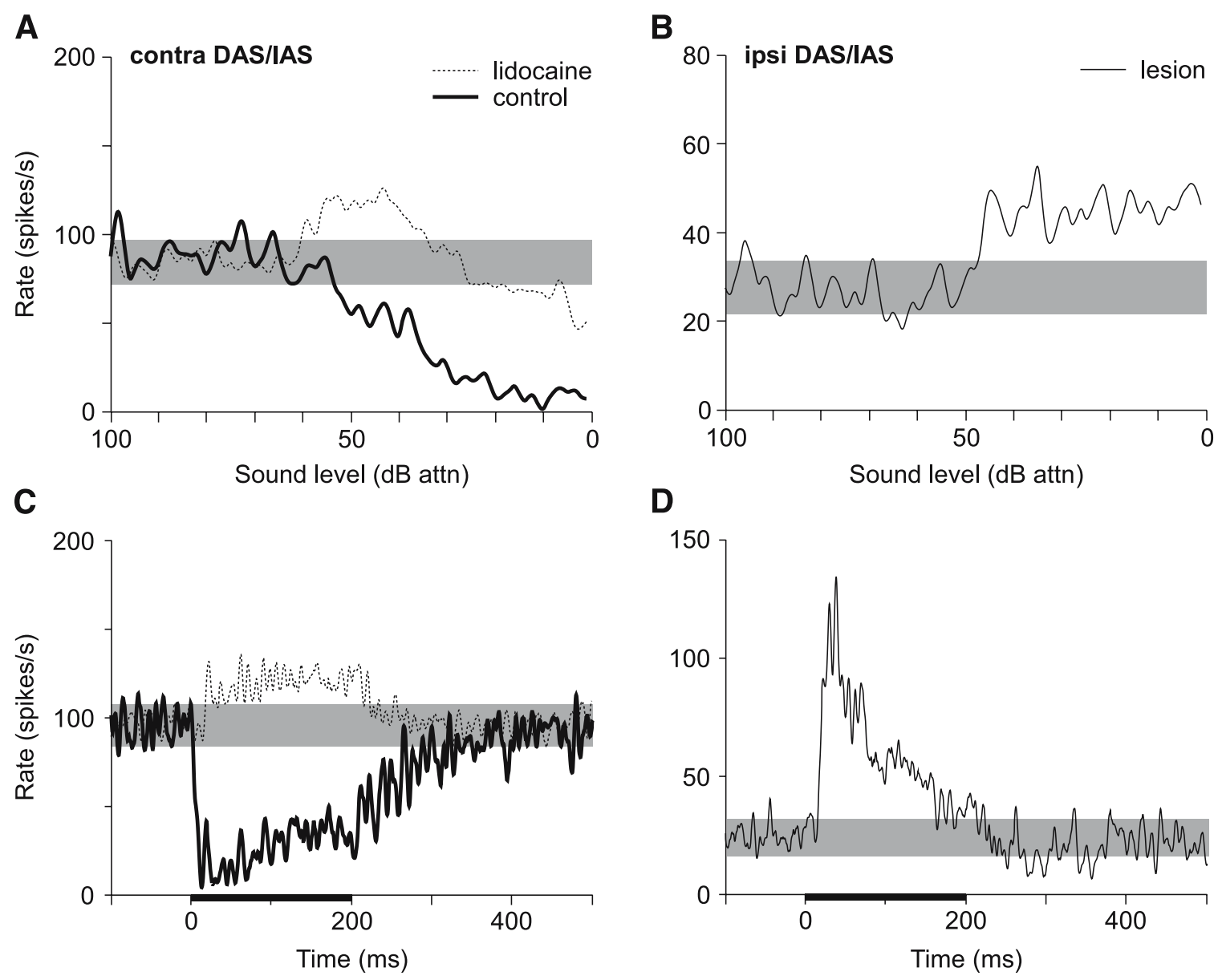

FIG. 7. Effects of blockade of the contralateral (left) and ipsilateral (right) acoustic striae on the responses of DCN type IV units to contralateral broadband noise. A, C: Plots show discharge rate vs. noise level functions (A) and PSTHs (C) for a type IV unit (98/09/02, unit $5.01, B F=24 \mathrm{kHz}$ ) before (heavy solid lines) and $5 \mathrm{~min}$ after (dotted lines) pressure injection of lidocaine into the contralateral dorsal (DAS) and intermediate acoustic striae (IAS). The shaded bars

The strong binaural effects described above for noise suggest that contralateral ear stimulation would be significant in natural sounds fields, where different azimuthal sounds source positions generate ILDs with reciprocal level changes in the two ears (Musicant et al. 1990; Rice et al. 1992). Figure 9A and B shows spatial receptive fields of a representative type IV unit to monaural and binaural virtual space (VS) stimuli, respectively. The VS stimuli were synthesized at 99 locations in the frontal field, at azimuths and elevations where the gridlines intersect, by filtering broadband noise with generic HRTFs (Rice et al. 1992). For recordings in the left DCN, negative azimuths indicate sounds in the ipsilateral hemifield; positive elevations indicate source locations above the horizontal plane. Firing rates at each stimulus location are color-coded (bar to the right) such that

show the range of SR. Note that blockade of the contralateral DAS/ IAS blocks, in part, the inhibitory responses of type IV units to contralateral noise, including the onset of inhibition, and reveals underlying excitation. B, D: Noise rate-level function (B) and PSTH (D) for a type IV unit $(98 / 10 / 20$, unit $6.02, \mathrm{BF}=33.5 \mathrm{kHz})$ after the ipsilateral DAS/IAS is surgically cut. Type IV units are strictly excited by contralateral stimulation after this manipulation.

high discharge rates are shown in red and low rates are shown in blue and black. In response to monaural VS stimuli (Fig. 9A), the type IV unit showed a tuned inhibitory response (blue area) that followed a diagonal contour from low ipsilateral to high contralateral elevations. This trough in the elevation functions coincided with a spectral notch in the HRTF at the unit's nominal BF $[12 \mathrm{kHz}$; the sampling rate of VS stimuli was altered for each unit tested to shift in effect the BF of the unit to the approximate center of the frequency range (5-18 $\mathrm{kHz}$ ) where cat HRTFs show directionally dependent spectral notches]. When tested with binaural VS stimuli (Fig. 9B), the unit showed weaker excitatory responses and a deeper inhibitory trough in ipsilateral space and inhibition throughout much of contralateral space. 
A

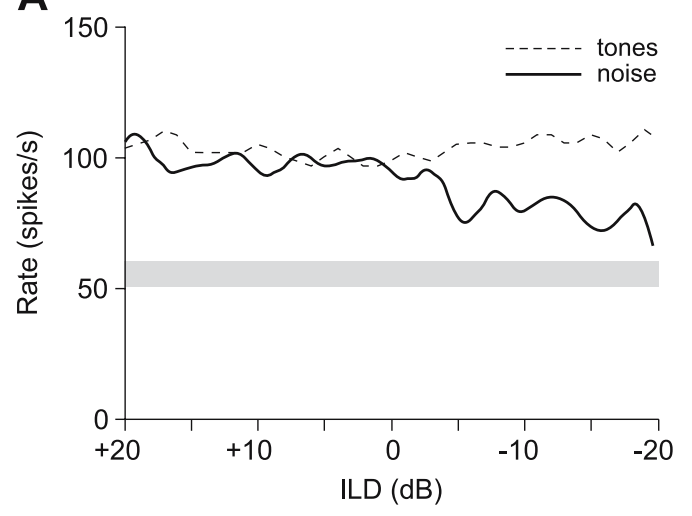

B

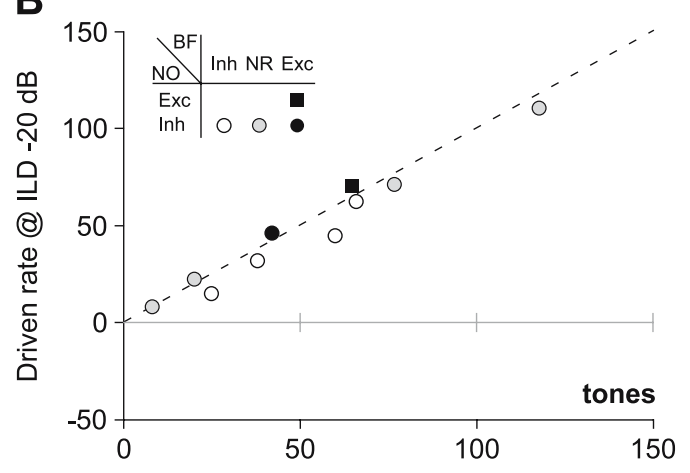

C

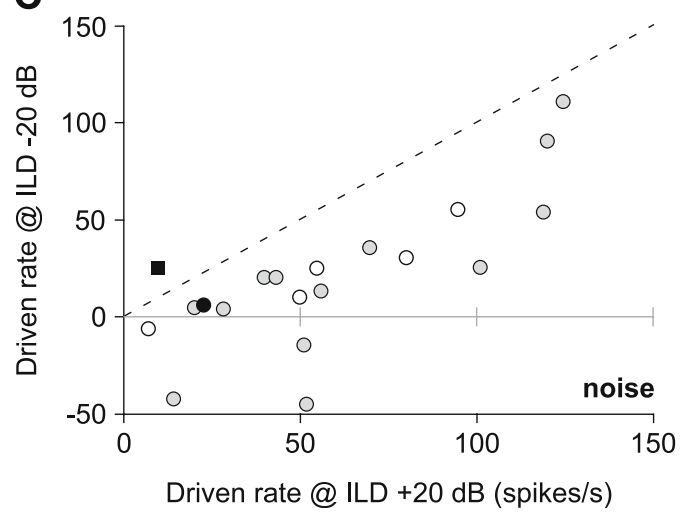

FIG. 8. Sensitivity of DCN type IV units to interaural level differences (ILDs). (A) Tone (dashed line) and noise (solid line) ILD functions for a type IV unit $(99 / 07 / 08$, unit 5.03, BF $=27.5 \mathrm{kHz})$. The level of the ipsilateral stimulus was held constant at $10 \mathrm{~dB}$ re ipsilateral threshold, whereas the contralateral level was varied from $20 \mathrm{~dB}$ below ( $+20 \mathrm{~dB}$ ILD condition) to $20 \mathrm{~dB}$ above $(-20 \mathrm{~dB}$ ILD condition) this level. Note that changes in discharge rate are greater for increasing levels of contralateral noise than for tones. B, C: Comparisons of each unit's driven rate for tones $(\mathbf{B})$ and noise $(\mathbf{C})$ at an ILD of $-20 \mathrm{~dB}$ vs. an ILD of $+20 \mathrm{~dB}$. Symbols indicate the effect of contralateral tones and noise on each unit (see legend). Symbols falling along the dashed line indicate units that showed no change in driven rate under the two binaural conditions. Note that the changes are larger for noise than for tones.

The effects of binaural versus monaural stimulation on the strength of inhibition were quantified by comparing the magnitude of inhibition at elevations along the 12-kHz notch contour as a function of azimuth. Curves connecting the median rates for six class oi units are shown in Figure 9C. The green plots indicate responses to monaural stimulation, whereas the red plots indicate responses to binaural stimulation. Nonparametric statistical tests indicated that azimuth had no significant effect on the strength of inhibition ( $P=0.53$; Friedman's test $)$; however, inhibitory responses to binaural stimulation were significantly stronger than responses to monaural stimulation $(P=0.02$; median change of 9 spikes $/ \mathrm{s})$. The ability of binaural stimulation to affect driven rates even at the edges of ipsilateral space tested here most likely reflects the fact that the levels of VS stimuli were usually well above $(\sim 30 \mathrm{~dB}$ above $)$ ipsilateral thresholds to noise, and thus above contralateral thresholds to noise as well.

Dorsal cochlear nucleus type IV units showed distinct changes in the extent of inhibitory response areas in their spatial receptive fields from monaural to binaural stimulus conditions. Figure 9D shows the borders of these areas for monaural (green curves) and binaural stimulation (red curves) as a function of azimuth. The curves connect the median values at each azimuth. Note that under monaural stimulus conditions, the inhibitory area is tuned along the 12$\mathrm{kHz}$ notch contour (dashed line) from low ipsilateral to high contralateral elevations. In contrast, the inhibitory area widens significantly in the contralateral hemifield (positive azimuths) under binaural stimulus conditions. The effect of this change is to reduce the selectivity of type IV units for notches in the contralateral field (i.e., to lateralize the response to the ipsilateral hemifield).

\section{DISCUSSION}

Comparisons with previous studies

In the present study, DCN principal cell responses to contralateral monaural tones and noise could be grouped into four distinct classes (Figs. 2 and 3). Most type IV units were weakly $(30 \%)$, if at all (52\%), inhibited by tones, but were strongly inhibited by noise. The remainder of the units was excited by tones and either inhibited (11\%) or excited by noise $(7 \%)$. These results are largely consistent with those of previous studies. In particular, Young and Brownell (1976) found the same range of response classes and similar incidence rates in an earlier study in decerebrate cats. Mast $(1970,1973)$ found that approximately $20 \%$ of DCN cells in anesthetized chinchilla were inhibited by contralateral tones, whereas $10 \%$ of units in an unanesthetized preparation were excited. Finally, Joris and Smith (1998) found that $50 \%$ of a limited sample of units in 
A

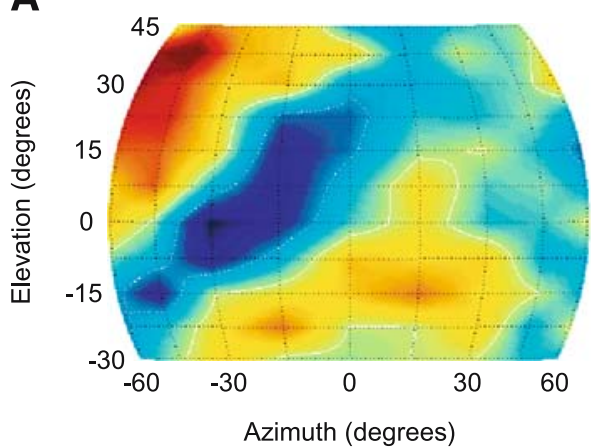

C

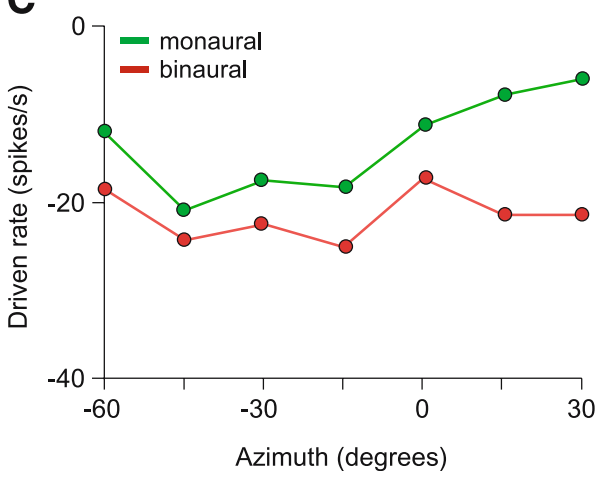

FIG. 9. Comparison of monaural and binaural spatial receptive fields of DCN type IV units. (A, B) Spatial receptive field for a type IV unit $(04 / 04 / 07$, unit $3.05, B F=16.5 \mathrm{kHz})$ in response to ipsilateral monaural (A) and binaural virtual space (VS) stimulation (B). Cat head-related transfer functions (HRTFs) were used to synthesize monaural and binaural VS stimuli at azimuths and elevations where the gridlines intersect. The sampling rate of these stimuli was adjusted for each unit to shift in effect the BF of the unit to 12 $\mathrm{kHz}$. Firing rates at each stimulus location are color-coded (bar to the right). White solid (dotted) lines enclose regions of rate that exceed 1 standard deviation above (below) the SR. Note that in response to monaural stimulation, the unit achieved its lowest discharge rates (blue) along a diagonal contour connecting low

anesthetized cat showed weak inhibition to tones, whereas $100 \%$ of DCN principal cells were strongly inhibited by contralateral noise. The lack of excitation in their study may be because of the effects of anesthesia, which is known to abolish contralateral excitatory effects (Mast 1973).

Consistent with their respective monaural effects, contralateral tones had only weak effects on ipsilaterally evoked activity, whereas contralateral noise had strong effects (Fig. 8). In particular, ILD curves for tones were relatively flat as a function of increasing contralateral level, whereas binaural BBN responses decreased with level. In agreement with these results, Young and Brownell (1976) reported that binaural responses to diotic tones (ILD $=0-\mathrm{dB}$ condition) as a function of stimulus level were essentially the same as responses to ipsilateral tones. Binaural noise responses, on the other hand, were found to be inter-
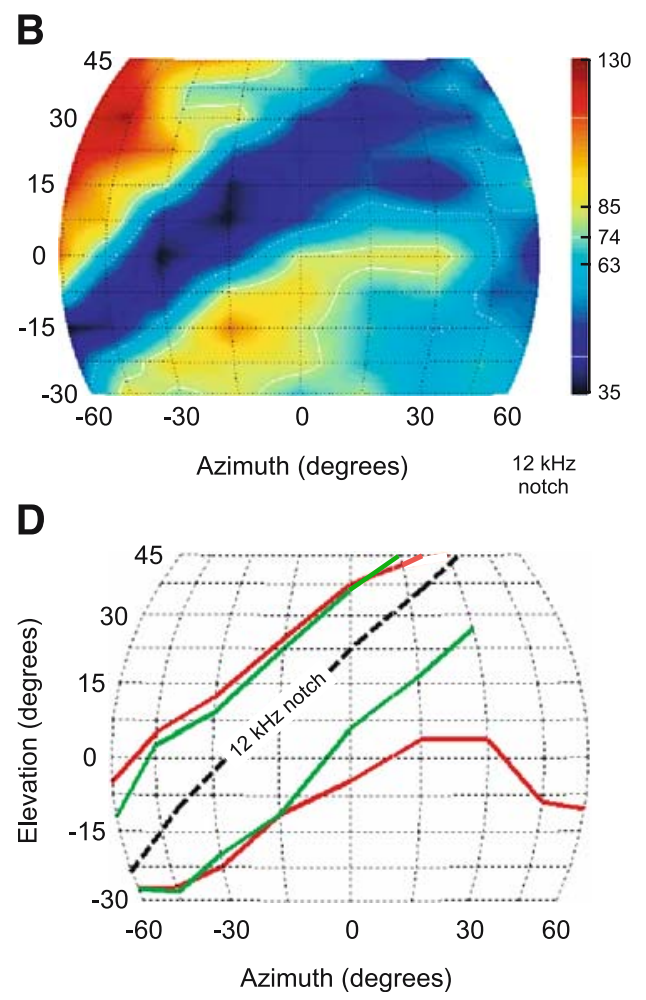

ipsilateral elevations with high contralateral elevations. The binaural response is more strongly inhibited along this contour, but also shows a loss of specificity in the contralateral field (i.e., the region of inhibition expands). (C) Median driven rates of type IV units at the $12-\mathrm{kHz}$ notch elevation as a function of azimuth for monaural (green) and binaural (red) stimulation. The rates to binaural stimulation are significantly lower $(P<0.05$, Friedman test $)$ than those to monaural stimulation at all azimuths. (D) Median lower and upper edges of inhibition in the responses of type IV units to monaural (green lines) and binaural VS stimulation (red lines). The dashed line indicates the trajectory of the $12-\mathrm{kHz}$ notch contour. Note that the inhibitory area widens in the contralateral hemifield (positive azimuths) under binaural stimulus conditions.

mediate between excitatory ipsilateral and inhibitory contralateral responses. Interestingly, tone ILD curves in chinchilla were found to decrease markedly with increasing contralateral level suggesting a strong effect of contralateral tones (Mast 1970). This difference could reflect an anesthetic effect (i.e., a potentiation of GABAergic inputs; Richter and Holtman 1982) or a species difference. Finally, Joris and Smith (1998) reported that noise ILD curves were flat as compared with those found in the lateral superior olive. However, they found decreases in firing rates with increasing contralateral level on the order of 30-40 spikes/s, which are comparable to the values shown here.

Stimulation of the contralateral ear had significant effects on type IV unit responses to natural sound fields (Fig. 9). In response to monaural VS stimuli, type IV units showed a tuned inhibitory response that 
followed a diagonal contour from low ipsilateral to high contralateral elevations. This trough in the elevation functions coincided with a spectral notch in the HRTF at the unit's BF. When tested with binaural VS stimuli, type IV units showed a deeper inhibitory trough in the ipsilateral hemifield and inhibition throughout much of contralateral space. Imig et al. (2000) also found that DCN principal cells in anesthetized cat showed response nulls in their azimuth functions to free-field monaural and binaural noise. Furthermore, spatial receptive fields showed that these response nulls followed the expected trajectory of spectral notches. The depth of modulation was slightly greater for binaural than monaural noise showing that contralateral inhibition had a small but significant effect on unit directionality.

\section{A conceptual model of contralateral inputs to type IV units}

The results of this study suggest that DCN type IV units receive inputs from at least three distinct sources of contralateral input (Fig. 10): one glycinergic (onset chopper; $\mathrm{O}_{\mathrm{c}}$ ), one GABAergic, and one excitatory (ventral nucleus of the trapezoid body; VNTB). The evidence for this model is discussed below.

The prototypic type IV unit is weakly, if at all, inhibited by contralateral tones, but is strongly inhibited by noise (Figs. 2 and 3). This inhibition is, in part, glycinergic and short latency (Fig. 6; Evans and Zhao 1993; Mast 1970; Joris and Smith 1998) and carried by commissural axons (Fig. 7A and C). Several lines

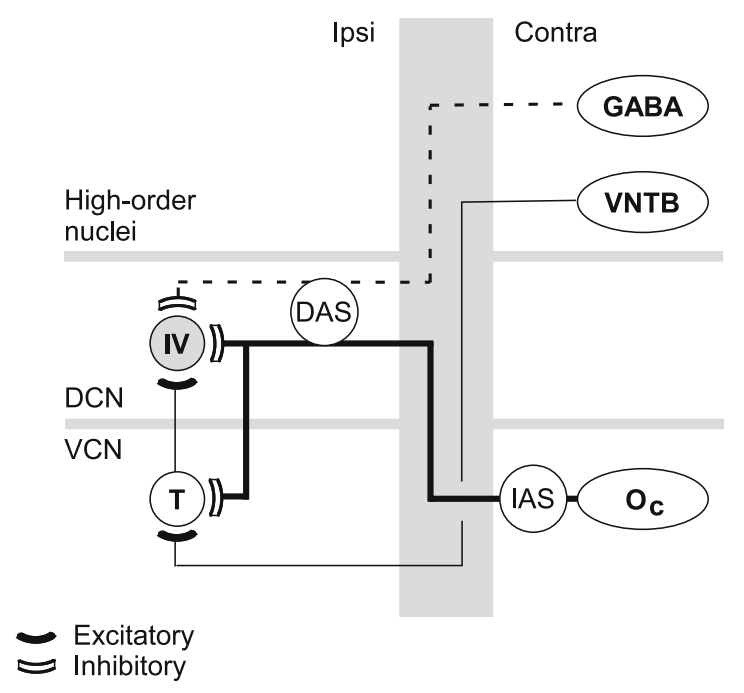

FIG. 10. Model of contralateral inputs to the DCN. Filled symbols are excitatory connections, and empty symbols are inhibitory connections. Putative glycinergic connections are heavy solid lines, and GABAergic connections are dashed lines. IV, type IV unit; T, Tstellate cell; DAS, dorsal acoustic stria; VNTB, ventral nucleus of the trapezoid body; $\mathrm{O}_{\mathrm{C}}$, onset- $\mathrm{C}$ unit; IAS, intermediate acoustic stria. of evidence suggest that $\mathrm{O}_{c}$ units in the contralateral VCN are the source of this inhibition. First, $\mathrm{O}_{c}$ units (large multipolar cells, Smith and Rhode 1989) respond more strongly to BBN than to tones (Winter and Palmer 1995; Palmer et al. 1996). Second, $\mathrm{O}_{\mathrm{c}}$ units have very short response latencies, especially compared with those of DCN neurons (Rhode and Smith 1986a, b; Joris and Smith 1998), allowing for ample time to provide near-coincident input with ipsilateral inputs. Finally, the commissural pathway arises primarily from large multipolar cells in the VCN (Cant and Gaston 1982; Shore et al. 1992; Schofield and Cant 1996) that are glycinergic (Wenthold 1987; Ostapoff et al. 1997; Alibardi 2000; Babalian et al. 2002). Recent studies have shown that at least some of these cells have $\mathrm{O}_{c}$ responses to sound (Needham and Paolini 2003; Arnott et al. 2004). In addition, it appears from Arnott et al. that the axons of $\mathrm{O}_{c}$ units travel across the brainstem near the fibers of the IAS. The results of the current study are consistent with this observation as pharmacological manipulation of the contralateral IAS, but not DAS, blocked the contralateral shortlatency inhibition.

The possibility of glycinergic inputs from a more diverse population of cells, most notably from periolivary neurons in the superior olivary complex (SOC) (Ostapoff et al. 1990, 1997), cannot be ruled out. However, response latencies for neurons in these nuclei are long in comparison to those of auditory nerve fibers (e.g., Tsuchitani 1977; Liberman and Brown 1986). Thus, such inputs are likely to contribute only to the later, sustained portion of the inhibition.

The inhibition of type IV units is also, in part, GABAergic and long latency (Fig. 6). The largest extrinsic sources of GABAergic input to the DCN are from the periolivary nuclei within the SOC (Ostapoff et al. 1990, 1997). Most of the GABA-immunoreactive cells that project to the DCN are located bilaterally in the VNTB. The VNTB contains a heterogeneous group of cells, which are known to receive ascending input from the VCN (Robertson and Winter 1988; Thompson and Thompson 1991; Smith et al. 1993) as well as descending inputs from a variety of sources (Vetter et al. 1993; Mulders and Robertson 2000). The response properties of all the different cell types in the VNTB have not been studied systematically. In general, however, VNTB neurons are driven by tones and noise, through one or both ears, and have response latencies that are delayed on the order of 5$10 \mathrm{~ms}$ with respect to activity in auditory nerve fibers (Goldberg and Brown 1968; Guinan et al. 1972a, b; Liberman and Brown 1986).

The model assumes a source of excitation to type IV units to account for units that are excited by tones 
and noise (Figs. 2 and 3). This excitatory source has a long latency (Fig. 5B and D; Mast 1973), and its axons must enter the DCN via a ventral route (Fig. 7B and $\mathrm{D}$ ). A strong candidate for this source is a circuit that includes neurons in the VNTB and $\mathrm{T}$ stellate cells in the VCN. The VNTB contains two distinct groups of cholinergic cells, medial olivocochlear (MOC) neurons and small cells, which provide all of the cholinergic input to the VCN (Sherriff and Henderson 1994). The efferent fibers of MOC neurons project to outer hair cells in the cochlea, but also give off collateral branches within the vestibular nerve root that contact the dendrites of stellate cells in the VCN (Benson and Brown 1990; Brown and Benson 1992). The small cells project to the magnocellular region of the VCN through the trapezoid body (Sherriff and Henderson 1994). In turn, in vitro studies suggest that $\mathrm{T}$ stellate cells excite DCN principal cells (Oertel et al. 1990; Zhang and Oertel 1993b, 1994).

Several lines of evidence suggest that contralateral acoustic stimulation could elicit long-latency excitation of $\mathrm{T}$ stellate cells (chopper units, Smith and Rhode 1989). First, MOC neurons, and VNTB neurons in general, are driven by tones or noise, through one or both ears, and have long response latencies (Goldberg and Brown 1968; Guinan et al. 1972a, b; Liberman and Brown 1986; Liberman 1988; Brown et al. 1998). Second, T stellate cells are excited by application of cholinergic agonists (Fujino and Oertel 2001) suggesting that activity of either the MOC or small cells in the VNTB would likely excite $\mathrm{T}$ stellate cells. Consistent with this hypothesis, Mulders et al. (2002) found that electrical stimulation of the MOC, after the olivocochlear effect was eliminated, elicited excitation in some VCN chopper units. However, other chopper units were inhibited suggesting a dual action of MOC efferents. Third, Needham and Paolini (2003) found that contralateral tones elicited sustained excitatory postsynaptic potentials in chopper units with a delay of 7-10 ms. Similarly, chopper units showed a short-latency membrane hyperpolarization after stimulation of the contralateral ear with noise that was soon exceeded by excitatory inputs (latency of $\sim 14 \mathrm{~ms}$ ). Finally, Shore et al. (2003) found that $30 \%$ of VCN units in anesthetized guinea pig were inhibited by contralateral stimulation, but that $4.5 \%$ of cells were excited.

The possibility of other sources of excitatory input to DCN type IV units cannot be ruled out. For example, there is considerable heterogeneity in the neurons that contribute to the commissure (Shore et al. 1992; Schofield and Cant 1996; Alibardi 2000). Some of these neurons are immunonegative for both glycine and GABA (Alibardi 2000) and thus presumably excitatory. In addition, some projections from the periolivary nuclei are also immunonegative for both glycine and GABA (Ostapoff et al. 1997). Finally, projections from the inferior colliculus may be glutamatergic and excitatory (Saint Marie 1996).

\section{Functional implications}

Behavioral studies have shown that cats are capable of localizing the source of broadband sounds in the frontal field with considerable accuracy (May and Huang 1996). This accuracy is maintained when the bandwidth of stimuli is narrowed to contain energy from 5 to $18 \mathrm{kHz}$, but is lost when mid-frequency cues are removed by high-pass filtering or narrowing the bandwidth of the stimulus to mid-frequency pure tones (Huang and May 1996). Studies of the filter functions that describe the transformation of a freefield sound to the energy spectrum at the eardrum suggest that a directionally dependent spectral notch at mid-frequencies may be the cue to localizing broadband sounds (Musicant et al. 1990; Rice et al. 1992). Interestingly, notch frequency does not represent a single point in space, but rather a contour that connects low ipsilateral to high contralateral elevations. The ambiguity along this line could be resolved by information from low and high frequencies, from binaural time and level disparity cues (Middlebrooks and Green 1991), or knowledge of the notch frequency in the contralateral ear (the binaural first notch direction code or BiFiND code; Rice et al. 1992).

Electrophysiological studies in cats have shown that the projection neurons of the DCN are especially sensitive to spectral notches (Young et al. 1992; Imig et al. 2000; this study). Type IV units are inhibited by tones, but give excitatory responses to broadband noise (Young and Brownell 1976). When a spectral notch is added to noise near BF, type IV units show an inhibitory response (Spirou and Young 1991). Thus, type IV units show a tuned inhibition for a spectral notch at their BF. Furthermore, the spatial receptive fields of DCN principal cells show response nulls that follow the expected diagonal trajectory of spectral notches (Imig et al. 2000; this study). These observations suggest that the DCN serves as an early stage in the processing of HRTF-based sound localization cues. Consistent with this interpretation, lesioning the output pathway of the DCN disrupts the sound localization performance of cats, particularly their orientation to sound source elevation (Sutherland et al. 1998; May 2000).

The results of present study show that DCN principal cells are generally inhibited by contralateral stimuli, particularly by broadband noise. The effects of the contralateral inputs on the spatial receptive fields of type IV units are twofold: stronger inhibitory 
responses to notches in ipsilateral space and primarily inhibitory responses in contralateral space. The former effect increases DCN sensitivity to spectral notches and is thus likely to enhance upstream processing of spectral cues. For example, type $\mathrm{O}$ units in the inferior colliculus are known to receive DCN inputs (Davis 2002) and to show tuned excitatory responses for notches located just below BF (Davis et al. 2003). The stronger inhibition exhibited by DCN units for notches at BF under binaural stimulus conditions would likely prevent the upward spread of excitation in type $\mathrm{O}$ units. The latter effect largely confines the sensitivity of DCN principal cells to sounds in ipsilateral space. This has clear implications for the BiFiND hypothesis because it restricts toward the midline the region of space where notch frequency may be known from both ears. This effect could also explain, in part, preliminary observations that type $\mathrm{O}$ units show spatial tuning for sounds primarily in one hemifield (Davis et al. 2003). More studies are needed to determine the extent to which binaural interactions in DCN impact the processing of spectral-dependent information in higher-order neurons.

\section{ACKNOWLEDGMENTS}

The author thanks Dr. Eric D. Young for support and encouragement, Drs. Nell Cant and Brett Schofield for helpful discussions, Oleg Lomakin for software development and for participating in some of the experiments, and YueHoung $\mathrm{Hu}$ and Oleg Lomakin for help in data analysis and figure preparation. This work was supported by National Institute of Deafness and Other Communication Disorders grants DC00979 (to E.D.Y.) and DC05161 (to K.A.D.).

\section{REFERENCES}

ADAMS JC, WARR WB. Origins of axons in the cat's acoustic striae determined by injection of horseradish peroxidase into severed tracts. J. Comp. Neurol. 170:107-121, 1976.

Alibardi L. Cytology, synaptology and immunocytochemistry of commissural neurons and their putative axonal terminals in the dorsal cochlear nucleus of the rat. Anat. Anz. 182:207-220, 2000.

Arnott RH, Wallace mn, Shackleton tM, Palmer AR. Onset neurones in the anteroventral cochlear nucleus project to the dorsal cochlear nucleus. J. Assoc. Res. Otolaryngol. 5:153-170, 2004.

Babalian AL, Ryugo DK, Vischer MW, Rouiller EM. Inhibitory synaptic interactions between cochlear nuclei: evidence from an in vitro whole brain study. NeuroReport 10:1913-1917, 1999.

Babalian Al, Jacomme AV, Doucet JR, Ryugo DK, Rouiller EM. Commissural glycinergic inhibition of bushy and stellate cells in the anteroventral cochlear nucleus. NeuroReport 13:555-558, 2002.
Benson TE, Brown MC. Synapses formed by olivocochlear axon branches in the mouse cochlear nucleus. J. Comp. Neurol. 295:52-70, 1990.

Brown MC, Benson TE. Transneuronal labeling of cochlear nucleus neurons by HRP-labeled auditory nerve fibers and olivocochlear branches in mice. J. Comp. Neurol. 321:645665, 1992.

Brown mC, Liberman MC, Benson TE, Ryugo DK. Brainstem branches from olivocochlear axons in cats and rodents. J. Comp. Neurol. 278:591-603, 1988.

Brown MC, Kujawa SG, Duca ML. Single olivocochlear neurons in the guinea pig. I. Binaural facilitation of responses to high-level noise. J. Neurophysiol. 79:3077-3087, 1998.

Cant NB, Gaston KC. Pathways connecting the right and left cochlear nuclei. J. Comp. Neurol. 212:313-326, 1982.

Conlee JW, Kane ES. Descending projections from the inferior colliculus to the dorsal cochlear nucleus in the cat: an autoradiographic study. Neuroscience 7:161-178, 1982.

DAVIS KA. Evidence of a functionally segregated pathway from dorsal cochlear nucleus to inferior colliculus. J. Neurophysiol. 87:1824-1835, 2002.

DAvis KA, Young ED. Pharmacological evidence of inhibitory and disinhibitory neuronal circuits in dorsal cochlear nucleus. J. Neurophysiol. 83:926-940, 2000.

Davis KA, Ramachandran R, May BJ. Single-unit responses in the inferior colliculus of decerebrate cats. II. Sensitivity to interaural level differences. J. Neurophysiol. 82:164-175, 1999.

Davis KA, Ramachandran R, May BJ. Auditory processing of spectral cues for sound localization in the inferior colliculus. J. Assoc. Res. Otolaryngol. 4:148-163, 2003.

Evans EF, Zhao W. Varieties of inhibition in the processing and control of processing in the mammalian cochlear nucleus. Prog. Brain Res. 97:117-126, 1993.

Fernandez C, Karapas F. The course and termination of the striae of Monakow and Held in the cat. J. Comp. Neurol. 131:371-386, 1967.

Fujino K, Oertel D. Cholinergic modulation of stellate cells in the mammalian ventral cochlear nucleus. J. Neurosci. 21:73727383, 2001.

GIBSON DJ. Interaural crosstalk in the cat. Hear. Res. 7:325-333, 1982.

Goldberg JM, Brown PB. Functional organization of the dog superior olivary complex: an anatomical and electrophysiological study. J. Neurophys. 31:619-656, 1968.

Guinan JJJ, Guinan SS, Norris BE. Single auditory units in the superior olivary complex. I. Responses to sounds and classification based on physiological properties. Int. J. Neurosci. 4:101120, 1972a.

Guinan JJJ, Guinan SS, Norris BE. Single auditory units in the superior olivary complex. II. Locations of unit categories and tonotopic organization. Int. J. Neurosci. 4:147-166, 1972b.

Havey DC, Caspary DM. A simple technique for constructing 'piggyback' multibarrel microelectrodes. Electroencephalogr. Clin. Neurophysiol. 48:249-251, 1980.

Huang AY, May BJ. Sound orientation behavior in cats. II. Midfrequency spectral cues for sound localization. J. Acoust. Soc. Am. 100:1070-1080, 1996.

Imig TJ, Bibikov NG, Poirier P, SAmson FK. Directionality derived from pinna-cue spectral notches in cat dorsal cochlear nucleus. J. Neurophysiol. 83:907-925, 2000.

JoRIs PX, SмITH PH. Temporal and binaural properties in dorsal cochlear nucleus and its output tract. J. Neurosci. 18:1015710170, 1998.

Liberman MC. Response properties of cochlear efferent neurons: monaural vs. binaural stimulation and the effects of noise. J. Neurophysiol. 60:1779-1798, 1988. 
Liberman MC, Brown MC. Physiology and anatomy of single olivocochlear neurons in the cat. Hear. Res. 24:17-36, 1986.

Manis PB, Spirou GA, Wright DD, Paydar S, Ryugo DK. Physiology and morphology of complex spiking neurons in the guinea pig dorsal cochlear nucleus. J. Comp. Neurol. 348:261-276, 1994.

MAST TE. Binaural interaction and contralateral inhibition in dorsal cochlear nucleus of the chinchilla. J. Neurophysiol. 33:108-115, 1970.

MAST TE. Dorsal cochlear nucleus of the chinchilla: excitation by contralateral sound. Brain Res. 62:61-70, 1973.

MAY BJ. Role of the dorsal cochlear nucleus in the sound localization behavior of cats. Hear. Res. 148:74-87, 2000.

MaY BJ, Huang AY. Sound orientation behavior in cats. I. Localization of broadband noise. J. Acoust. Soc. Am. 100:1059-1069, 1996.

Middlebrooks JC, Green DM. Sound localization by human listeners. Annu. Rev. Psychol. 42:135-159, 1991.

Mulders WH, Robertson D. Evidence for direct cortical innervation of medial olivocochlear neurones in rats. Hear. Res. 144:6572, 2000.

Mulders WH, Winter IM, Robertson D. Dual action of olivocochlear collaterals in the guinea pig cochlear nucleus. Hear. Res. 174:264-280, 2002

Musicant AD, Chan JC, Hind JE. Direction-dependent spectral properties of cat external ear: new data and cross-species comparisons. J. Acoust. Soc. Am. 87:757-781, 1990.

Needham K, Paolini AG. Fast inhibition underlies the transmission of auditory information between cochlear nuclei. J. Neurosci. 23:6357-6361, 2003.

NeLken I, Young ED. Linear and nonlinear spectral integration in type IV neurons of the dorsal cochlear nucleus. I. Regions of linear interaction. J. Neurophysiol. 78:790-799, 1997.

Oertel D, Wu S, Garb MW, Dizak C. Morphology and physiology of cells in slice preparations of the posteroventral cochlear nucleus of mice. J. Comp. Neurol. 295:136-154, 1990.

Osen KK. Course and termination of the primary afferents in the cochlear nuclei of the cat. Arch. Ital. Biol. 108:21-51, 1970.

Ostapoff EM, Morest DK, Potashner SJ. Uptake and retrograde transport of $[3 \mathrm{H}] \mathrm{GABA}$ from the cochlear nucleus to the superior olive in the guinea pig. J. Chem. Neuroanat. 3:285-289, 1990.

Ostapoff EM, Benson CG, Saint Marie RL. GABA- and glycineimmunoreactive projections from the superior olivary complex to the cochlear nucleus in guinea pig. J. Comp. Neurol. 381:500-511, 1997.

Palmer AR, Jiang D, Marshall DH. Responses of ventral cochlear nucleus onset and chopper units as a function of signal bandwidth. J. Neurophysiol. 75:780-794, 1996.

Park TJ, Pollak GD. GABA shapes sensitivity to interaural intensity disparities in the mustache bat's inferior colliculus: implications for encoding sound location. J. Neurosci. 13:20502067, 1993.

Rhode WS, Smith PH. Encoding timing and intensity in the ventral cochlear nucleus of the cat. J. Neurophysiol. 56:261286, 1986a.

Rhode WS, Sмith PH. Physiological studies on neurons in the dorsal cochlear nucleus of cat. J. Neurophysiol. 56:287-307, 1986b.

Rice JJ, May BJ, Sirou GA, Young ED. Pinna-based spectral cues for sound localization in cat. Hear. Res. 58:132-152, 1992.

Richter JA, Holtman JR. Barbiturates: their in vivo effects and potential biochemical mechanisms. Neurobiology 18:275-319, 1982.

Robertson D, Winter IM. Cochlear nucleus inputs to olivocochlear neurones revealed by combined anterograde and ret- rograde labeling in the guinea pig. Brain Res. 462:47-55, 1988.

Ryugo DK, MAY BJ. The projections of intracellularly labeled auditory nerve fibers to the dorsal cochlear nucleus of cat. J. Comp. Neurol. 329:20-35, 1993.

SAINT MARIE RL. Glutamatergic connections of the auditory midbrain: selective uptake and axonal transport of D- $[3 \mathrm{H}]$ aspartate. J. Comp. Neurol. 373:255-270, 1996.

SchOFIELD BR. Origins of projections from the inferior colliculus to the cochlear nucleus in guinea pigs. J. Comp. Neurol. 429:206220, 2001.

Schofield BR, CANT NB. Origins and targets of commissural connections between the cochlear nuclei in guinea pigs. J. Comp. Neurol. 375:128-146, 1996.

Sherriff FE, Henderson Z. Cholinergic neurons in the ventral trapezoid nucleus project to the cochlear nuclei in the rat. Neuroscience 58:627-633, 1994.

SHOFNER WP, Young ED. Excitatory/inhibitory response types in the cochlear nucleus: relationships to discharge patterns and responses to electrical stimulation of the auditory nerve. J. Neurophysiol. 54:917-939, 1985.

Shore SE, Godfrey DA, Helfert RH, Altschuler RA, Bledsoe SC Jr. Connections between the cochlear nuclei in guinea pig. Hear. Res. 62:16-26, 1992.

Shore SE, Sumner CJ, Bledsoe SC, Lu J. Effects of contralateral sound stimulation on unit activity of ventral cochlear nucleus neurons. Exp. Brain Res. 153:427-435, 2003.

Smith PH, Rhode WS. Structural and functional properties distinguish two types of multipolar cells in the ventral cochlear nucleus. J. Comp. Neurol. 282:595-616, 1989.

SмITh PH, Joris PX, YIN TC. Projections of physiologically characterized spherical bushy cell axons from the cochlear nucleus of the cat: evidence for delay lines to the medial superior olive. J. Comp. Neurol. 331:245-260, 1993.

SirRou GA, Young ED. Organization of dorsal cochlear nucleus type IV unit response maps and their relationship to activation by bandlimited noise. J. Neurophysiol. 66:1750-1768, 1991.

Sutherland DP, Masterton RB, Glendenning KK. Role of acoustic striae in hearing: reflexive responses to elevated sound-sources. Behav. Brain Res. 97:1-12, 1998.

Thompson AM, Thompson GC. Projections from the posteroventral cochlear nucleus to the superior olivary complex in guinea pig: light and EM observations with the PHA-L method. J. Comp. Neurol. 311:495-508, 1991.

Tsuchitani C. Functional organization of lateral cell groups of cat superior olivary complex. J. Neurophysiol. 40:296-318, 1977.

Vetter De, Saldana E, Mugnaini E. Input from the inferior colliculus to medial olivocochlear neurons in the rat: a double label study with PHA-L and cholera toxin. Hear. Res. 70:173186, 1993.

Weedman DL, Rrugo DK. Projections from auditory cortex to the cochlear nucleus in rats: synapses on granule cell dendrites. J. Comp. Neurol. 371:311-324, 1996.

Wenstrup JJ, Fuzessery ZM, Pollak GD. Binaural neurons in the mustache bat's inferior colliculus. II. Determinants of spatial responses among 60-kHz EI units. J. Neurophysiol. 60:13841404, 1988.

WENTHOLD RJ. Evidence for a glycinergic pathway connecting the two cochlear nuclei: an immunocytochemical and retrograde transport study. Brain Res. 415:183-187, 1987.

Winter IM, Palmer AR. Level dependence of cochlear nucleus onset unit responses and facilitation by second tones or broadband noise. J. Neurophysiol. 73:141-159, 1995. 
Young ED. Identification of response properties of ascending axons from dorsal cochlear nucleus. Brain Res. 200:23-38, 1980.

Young ED, Brownell WE. Responses to tone and noise of single cells in dorsal cochlear nucleus of unanesthetized cats. J. Neurophysiol. 39:282-300, 1976.

Young ED, Sirrou GA, Rice JJ, Voigt HF. Neural organization and responses to complex stimuli in the dorsal cochlear nucleus. Philos. Trans. R. Soc. Lond., B 336:407-413, 1992.
Zhang S, Oertel D. Cartwheel and superficial stellate cells of the dorsal cochlear nucleus of mice: intracellular recordings in slices. J. Neurophysiol. 69:1384-1397, 1993a.

Zhang S, Oertel D. Giant cells of the dorsal cochlear nucleus of mice: intracellular recordings in slices. J. Neurophysiol. 69:1398-1408, 1993b.

Zhang S, Oertel D. Neuronal circuits associated with the output of the dorsal cochlear nucleus through fusiform cells. J. Neurophysiol. 71:914-930, 1994. 